\title{
Preparation and Purity Evaluation of 5N-Grade Ruthenium by Electron Beam Melting
}

\author{
J.-M. Oh, B.-K. Lee, H.-K. Park and J.-W. Lim* \\ Mineral Resources Research Division, Korea Institute of Geoscience and Mineral Resources, Daejeon 305-350, Korea
}

\begin{abstract}
In this study, we carried out an electron beam (EB) melting purification process to obtain a $5 \mathrm{~N}$-grade high-purity Ru ingot from commercial $\mathrm{Ru}$ powder. The first step was to primarily sinter $\mathrm{Ru}$ powder compact by means of vacuum heat treatment at $1,773 \mathrm{~K}$. Vacuum sintering was employed to ensure a high vacuum condition during EB melting by the removal of remaining gaseous elements between the compact powders. The second step was to obtain Ru ingots by EB melting of the sintered Ru compact. The purity of the Ru raw powder was 99.962 mass\% and the purity of a premelted Ru button ingot obtained by EB melting was 99.9873 mass \%. The purities of the respective Ru button ingots remelted for 2 and $4 \mathrm{~min}$ were 99.9988 and 99.9992 mass\%, respectively. As a result, the sum of metallic impurities in the Ru ingot refined for 6 min was 5.3 mass ppm and the purity of the ingot considerably increased up to 99.9995 mass \%, which means that a $5 \mathrm{~N}$-grade high-purity Ru ingot can be obtained by the EB melting purification process. Furthermore, the EB-melted Ru ingot showed an excellent ability to remove interstitial impurities. [doi:10.2320/matertrans.M2012155]
\end{abstract}

(Received April 24, 2012; Accepted June 6, 2012; Published August 25, 2012)

Keywords: ruthenium, high purity, purification, electron beam melting, grain size

\section{Introduction}

$\mathrm{Ru}$ has a higher melting temperature (about 2,607 K) than that of other platinum group metals (PGMs), while it also exhibits excellent corrosion resistance and catalytic properties. It is consequently an important material used in modern industry. ${ }^{1)}$ Most $\mathrm{Ru}$ is used for wear-resistant electrical contacts and in the production of plated films. Because of its lower cost and similar properties compared to other PGMs, especially rhodium, one of its major applications has been as a plating material for electronic contacts. A minor application of $\mathrm{Ru}$ is its use in some platinum alloys. ${ }^{2,3)}$ Recently, it has been increasingly used as a sputtering target material for magnetic recording and micro-fuel cells. ${ }^{4)}$ In the data storage industry, sputtering and chemical vapor deposition of $\mathrm{Ru}$ is used as a method for producing thin films on substrates. These thin films show promising properties for use in microchips and for the giant magnetoresistive read element of hard disk drives. ${ }^{5)}$ Thus, the data storage industry demands a sputtering target of high-purity Ru. For such sputtering targets, impurities in the material should be strictly controlled, and the purity of sputtering targets is gradually increasing from grade $4 \mathrm{~N}(99.99$ mass $\%)$ to $5 \mathrm{~N}(99.999$ mass\%). ${ }^{6}$ In conventional methods for obtaining highpurity $\mathrm{Ru}$ metal, $\mathrm{Ru}$ is first separated from other PGMs by hydrometallurgy before the impurities in the $\mathrm{Ru}$ metal are reduced by argon arc melting. However, current commercially available Ru ingots are limited to 4N5 (99.995 mass\%) grade purity.

Many researchers have studied the effects of high-temperature melting on the refining of pure metals. ${ }^{7-9)}$ It is known that electron beam (EB) melting at high vacuum is a very powerful technique for the refining of pure metals. ${ }^{10)}$ On the other hand, little research on the refining of $\mathrm{Ru}$ by $\mathrm{EB}$ melting has thus far been reported. Schriempf ${ }^{11)}$ reported that an $\mathrm{EB}$ zone refining process could be used to produce a final

*Corresponding author, E-mail: flashlim@kigam.re.kr
$5 \mathrm{~N}$-grade-purity $\mathrm{Ru}$ rod from commercial $\mathrm{Ru}$ powder that was 99.9 mass\% pure. However, the purity of the $5 \mathrm{~N}$-grade $\mathrm{Ru}$ rod in that instance was estimated by means of measuring the residual resistivity ratio (RRR) value only. For this reason, a precise impurity analysis is needed to confirm the purity of refined $\mathrm{Ru}$ metals. Recently, glow discharge mass spectrometry (GDMS) has been used to quantitatively determine trace elements for high-purity metals. GDMS is a direct solid-state analytical method (without any chemical process) that provides reliable quantitative concentrations below the ppb level for most elements. ${ }^{12}$ Therefore, in this work we have utilized the EB melting process to obtain an high-purity $\mathrm{Ru}$ ingot and evaluated the purity of the $\mathrm{Ru}$ ingot refined by the EB melting process using GDMS.

\section{Experimental}

EB melting equipment $(100 \mathrm{~kW}$ power, EMO100, VON ARDENNE Analgentechnik $\mathrm{GmbH}$ ) was used to obtain a $\mathrm{Ru}$ ingot. The purification process used in this study is shown schematically in Fig. 1. First, a Ru powder compact $(\phi 40 \mathrm{~mm})$ was made for button melting by weighing $120 \mathrm{~g}$ of $\mathrm{Ru}$ powder ( 99.9 mass\%, Vale, England). The Ru compact was then fabricated into a sintered form in a vacuum sintering furnace. The temperature and vacuum during the sintering process were $1,773 \mathrm{~K}$ and $5.0 \times 10^{-3} \mathrm{~Pa}$, respectively, and these were held for $1 \mathrm{~h}$. The vacuum sintering was performed to maintain a high vacuum condition during the EB melting by removing any residual gaseous elements from between the compact powders. The Ru compact was then loaded into a water-cooled copper mold in the melting chamber and the chamber was exhausted to a vacuum of $8.0 \times 10^{-3} \mathrm{~Pa}$. Premelted $\mathrm{Ru}$ button ingots were then prepared by twice melting the Ru compact at an EB power of $15 \mathrm{~kW}$ for $60 \mathrm{~s}$. The premelted $\mathrm{Ru}$ button ingots were turned upside down so that they were homogenized after the first melting at $20 \mathrm{~kW}$ and the total melting time for each of specimens was 2, 4 and 6 min, respectively. GDMS (Autoconcept GD90, MSI Ltd.) 


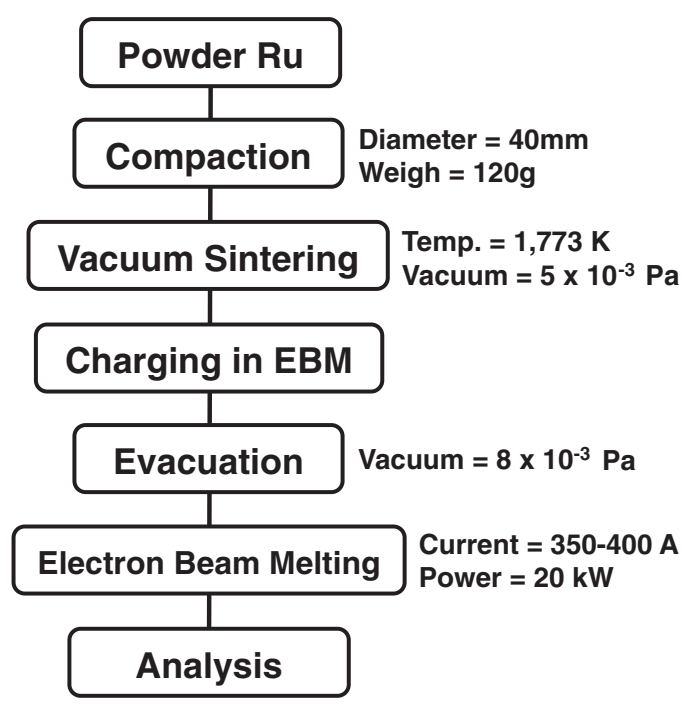

Fig. 1 Experimental procedure for the preparation of high-purity $\mathrm{Ru}$ ingots.

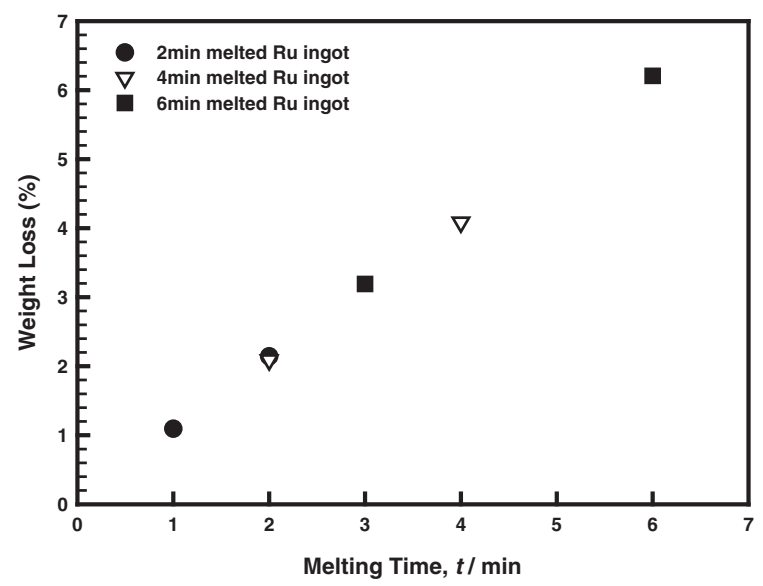

Fig. 2 Weight loss percentage in the $\mathrm{Ru}$ ingots as a function of melting time.

was used to analyze the purity of the Ru powder and button ingots. For the evaluation of purity, the Ru button ingot specimens were cut from the center of the ingot to $\phi 25 \mathrm{~mm}$ and polished using SiC paper and a microfiber cloth. After polishing, the specimens were ultrasonically cleaned. The crater diameter of glow discharge on each specimen was $12 \mathrm{~mm}$ in the present work. Furthermore, oxygen/nitrogen and carbon analyzers (LECO TCH-600, CS-600, LECO Inc.) were used to measure the gaseous impurities. The grain size of each specimen was observed with a micro/macroanalyzer (ImageInside, FOCUS Co., Ltd.).

\section{Results and Discussion}

To investigate the weight loss of the Ru button ingots upon multiple EB melting, we measured the weight of the $\mathrm{Ru}$ button ingots before and after EB melting. The resultant weight loss percentages as a function of melting time are shown Fig. 2. The weight loss of each $\mathrm{Ru}$ button ingot gradually increased until reaching a value of approximately $6.2 \%$ after EB melting for $6 \mathrm{~min}$. This weight loss during EB
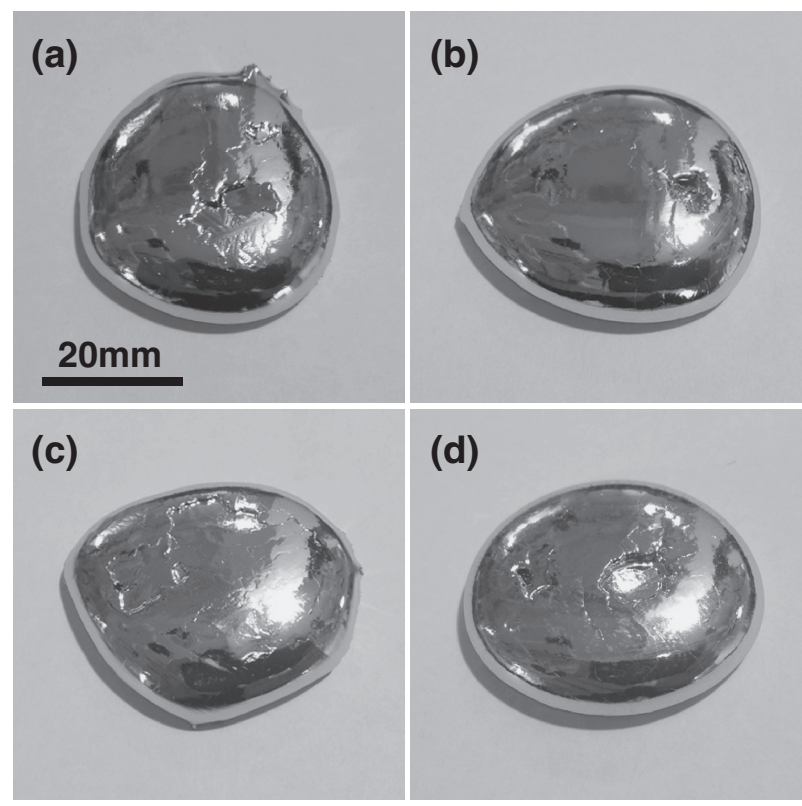

Fig. 3 The appearance of the Ru button ingots prepared by EB melting as a function of melting time; (a) premelted ingot, (b) $2 \mathrm{~min}$, (c) $4 \mathrm{~min}$ and (d) $6 \mathrm{~min}$.

melting can be attributed to the vaporization of the Ru matrix as well as to impurities with higher melting temperatures than that of $\mathrm{Ru}$ under a high vacuum. The appearance of each $\mathrm{Ru}$ button ingot after the corresponding melting condition is shown in Fig. 3. The Ru button ingots after EB melting were about $40 \mathrm{~mm}$ in diameter. It was also found that each specimen had a glossy metallic luster on the ingot surface after EB melting.

The variation in the concentrations of metallic impurities in the raw $\mathrm{Ru}$ powder and button ingots after EB melting is presented in Table 1 . The purity of the Ru raw powder was found to be 99.962 mass \%, while the purity of the button ingot premelted using the $\mathrm{Ru}$ powder was found to be 99.9873 mass \% . The purities of the respective $\mathrm{Ru}$ button ingots remelted for 2, 4 and 6 min were 99.9988, 99.9992 and 99.9995 mass \%, respectively. As a result, the total amount of impurities in the final $\mathrm{Ru}$ button ingot was 5.3 mass ppm, which means that a $5 \mathrm{~N}$-grade high-purity Ru button ingot can be prepared by a multiple EB melting purification process. The $R D$ (removal degree) with respect to each melting condition was calculated from eq. (1).

$$
R D=100\left(C_{\mathrm{i}}-C_{\mathrm{f}}\right) / C_{\mathrm{i}},
$$

where $C_{\mathrm{i}}$ (concentration of impurity) and $C_{\mathrm{f}}$ are the initial and final concentrations, respectively. The $R D_{\mathrm{av}}$ in Table 1 means the average of $R D$ for each impurity. From the initial impurity concentration, the $R D$ of the premelted $\mathrm{Ru}$ button ingot was approximately $66.5 \%$, while the Ru button ingots remelted for 2 and 4 min enhanced the $R D$ to approximately 96.9 and $98.0 \%$, respectively. The $R D$ of the Ru button ingot remelted for $6 \mathrm{~min}$ was approximately $98.6 \%$. Each $R D$ of metallic impurities and the vapor pressures with vapor pressure of $\mathrm{Ru}$ for the representative impurities in each $\mathrm{Ru}$ specimen were investigated and are illustrated in Fig. 4. The vapor pressure of $\mathrm{Ru}$ is approximately $9.27 \mathrm{~Pa}$ at melting temperature of $\mathrm{Ru}$ metal. The $R D$ of most impurities in the $\mathrm{Ru}$ specimens 
Table 1 Metallic impurities (massppm) in the raw $\mathrm{Ru}$ powder and $\mathrm{Ru}$ button ingots refined by EB melting (premelted and melted for 2, 4 and $6 \mathrm{~min})$.

\begin{tabular}{|c|c|c|c|c|c|}
\hline Element & $\mathrm{Ru}$ powder & Premelted & $2 \min$ & $4 \mathrm{~min}$ & $6 \mathrm{~min}$ \\
\hline $\mathrm{Na}$ & 19.1 & 3.76 & 0.83 & 0.48 & 0.34 \\
\hline $\mathrm{Mg}$ & 0.59 & 0.16 & 0.03 & 0.001 & N.D. \\
\hline $\mathrm{Al}$ & 1.36 & 0.39 & 0.27 & 0.29 & 0.17 \\
\hline $\mathrm{Si}$ & 16.9 & 1.24 & 1.00 & 0.94 & 0.56 \\
\hline $\mathrm{P}$ & 0.85 & 0.07 & 0.07 & 0.002 & 0.001 \\
\hline S & 1.37 & 0.71 & 0.20 & 0.12 & 0.06 \\
\hline $\mathrm{Cl}$ & 32.4 & 1.44 & 0.67 & 0.44 & 0.15 \\
\hline $\mathrm{Ca}$ & 202 & 80.2 & 1.29 & 0.13 & 0.08 \\
\hline $\mathrm{Ti}$ & 5.57 & 2.54 & 1.33 & 0.26 & 0.23 \\
\hline $\mathrm{V}$ & 24.0 & 16.0 & 0.17 & 0.02 & 0.03 \\
\hline $\mathrm{Cr}$ & 1.17 & 0.62 & 0.21 & 0.17 & 0.14 \\
\hline $\mathrm{Mn}$ & 0.97 & 0.21 & 0.09 & 0.02 & 0.02 \\
\hline $\mathrm{Fe}$ & 7.96 & 1.06 & 0.46 & 0.51 & 0.24 \\
\hline $\mathrm{Co}$ & 0.20 & 0.02 & 0.02 & 0.005 & 0.007 \\
\hline $\mathrm{Cu}$ & 1.36 & 0.50 & 0.50 & 0.41 & 0.59 \\
\hline $\mathrm{Zn}$ & 0.24 & 1.48 & 0.045 & 0.64 & 0.01 \\
\hline $\mathrm{Ge}$ & 2.94 & 0.71 & 0.69 & 0.59 & 0.35 \\
\hline $\mathrm{Se}$ & 3.88 & 1.20 & 0.03 & 0.04 & 0.12 \\
\hline $\mathrm{Pd}$ & 3.62 & 0.77 & 0.09 & 0.12 & 0.04 \\
\hline $\mathrm{Sn}$ & 48.9 & 12.5 & 1.48 & 0.32 & 0.35 \\
\hline $\mathrm{Sb}$ & 0.50 & 0.003 & N.D. & 0.003 & 0.002 \\
\hline $\mathrm{Te}$ & 0.81 & 0.02 & 0.002 & 0.02 & 0.012 \\
\hline W & 0.49 & 0.46 & 0.44 & 0.46 & 0.45 \\
\hline $\mathrm{Pt}$ & 3.01 & 1.32 & 1.60 & 1.52 & 1.24 \\
\hline $\mathrm{Au}$ & 0.13 & 0.03 & 0.005 & 0.01 & 0.04 \\
\hline $\mathrm{La}$ & 0.10 & 0.007 & 0.001 & 0.01 & 0.006 \\
\hline $\mathrm{Ce}$ & 0.06 & 0.005 & 0.007 & 0.02 & 0.007 \\
\hline $\mathrm{U}$ & 0.002 & 0.02 & 0.02 & 0.02 & N.D. \\
\hline $\begin{array}{l}\text { Metallic } \\
\text { impurities }\end{array}$ & 380.48 & 127.45 & 11.56 & 7.57 & 5.25 \\
\hline$R D_{\text {av }}(\%)$ & - & 66.50 & 96.96 & 98.01 & 98.62 \\
\hline $\begin{array}{l}\text { Purity (mass\%) } \\
(\text { except C, N, O) }\end{array}$ & 99.962 & 99.9873 & 99.9988 & 99.9992 & 99.9995 \\
\hline
\end{tabular}

increased with an increase in the vapor pressure of each element. As shown in Fig. 4, impurities such as Mn, Sn, Ca and $\mathrm{Mg}$ showed very high $R D$ in all $\mathrm{Ru}$ specimens, save that for the premelted $\mathrm{Ru}$ ingot. The $R D$ of these impurities reached approximately $99 \%$ after multiple EB melting had been carried out. In the case of $\mathrm{Si}$, Ti and Fe impurities, these elements, which have a vapor pressure less than $10^{5} \mathrm{~Pa}$, gave $R D$ values that were above approximately $95 \%$ for the $\mathrm{Ru}$ button ingot remelted for $6 \mathrm{~min}$. On the other hand, though the vapor pressure of $\mathrm{Pt}$ is approximately 10 times higher than that of $\mathrm{Ru}$, the $R D$ of Pt in the Ru button ingot was lower than might be expected based on a comparison of vapor pressures. This can be explained by the affinity of platinum group metals, where Pt is well known to be particularly difficult to remove and separate from $\mathrm{Ru}$, as exemplified by the $R D$ value of $58.9 \%$ for the Pt impurity herein, which is comparatively lower than the $R D$ for the other impurities in the samples. Of the remaining impurities, it is well known that $\mathrm{W}$ is difficult to remove from other metals under hightemperature melting conditions because it has a very low

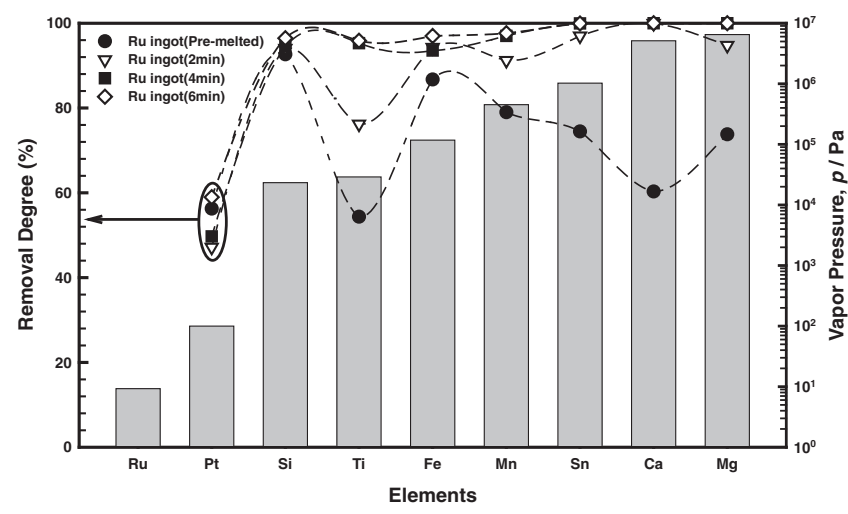

Fig. 4 Vapor pressures and the degrees of removal of representative impurities in the Ru button ingots refined by EB melting.

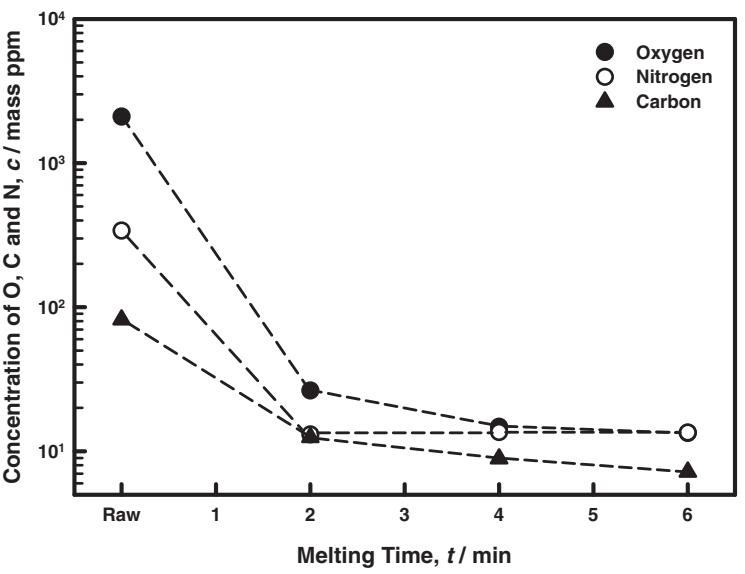

Fig. 5 Logarithm of $\mathrm{O}, \mathrm{N}$ and $\mathrm{C}$ concentrations in the raw $\mathrm{Ru}$ powder and $\mathrm{Ru}$ button ingots versus $\mathrm{EB}$ melting time.

vapor pressure compared to a matrix, which consequently leads to an accumulation of $\mathrm{W}$ in the matrix after each melting. ${ }^{13)}$ As shown in Table 1, no distinct change in the level of $\mathrm{W}$ impurity for each sample was found during EB melting. As mentioned above, the difference in the $R D$ value for each impurity can be explained by the difference in vapor pressure for each element, and as is shown in Fig. 4, the $R D$ value obtained upon multiple EB melting for each impurity is in good agreement with the vapor pressure of each element.

It is known that the mechanical properties of high melting temperature metals are dependent upon the concentration of gaseous impurities contained within them, such as $\mathrm{C}, \mathrm{N}$ and O. ${ }^{6)}$ A patent reported that a $\mathrm{Ru}$ sputtering target exhibited gaseous impurities, such as $\mathrm{C}, \mathrm{Cl}$ and $\mathrm{O}$, at a level below 100 mass ppm. ${ }^{14)}$ On the other hand, Hitachi Metals reported on a high-purity $\mathrm{Ru}$ target with a level of gaseous impurities $(\mathrm{Cl}, \mathrm{C}$ and $\mathrm{O})$ below 50 mass ppm using a plasma droplet refining method with HIP sintering technology. ${ }^{15)}$ The changes in concentration of the $\mathrm{C}, \mathrm{N}$ and $\mathrm{O}$ in the $\mathrm{Ru}$ powder and button ingots are shown in Fig. 5. In our experiments, the oxygen concentration quickly decreased from 2,100 to 113 mass ppm during the EB premelting process as the sample transitioned from a powder to ingot. After the additional EB melting for 2, 4 and $6 \mathrm{~min}$, the oxygen concentration decreased to 26,15 and 13 mass ppm, 

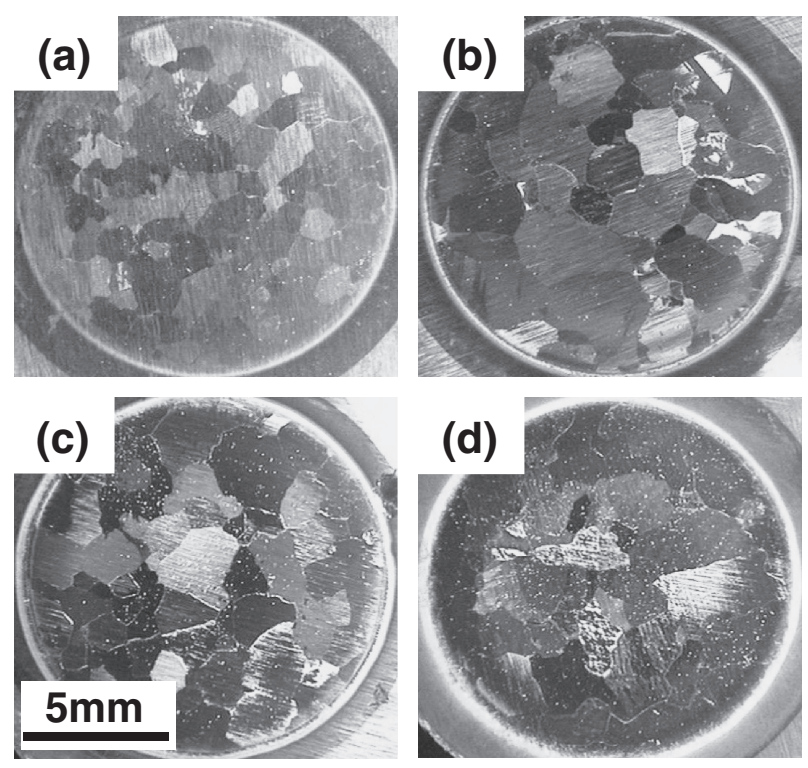

Fig. 6 Average grain size of Ru button ingots prepared by EB melting as a function of melting time; (a) premelted ingot, (b) $2 \mathrm{~min}$, (c) $4 \mathrm{~min}$ and (d) $6 \mathrm{~min}$.

respectively. In other words, it was found that EB melting provides excellent deoxidation conditions for $\mathrm{Ru}$ button ingots. Several researchers have studied the degassing of metals by high-temperature melting methods. ${ }^{16,17)}$ Waseda et al. reported a mechanism of degassing $(\mathrm{C}, \mathrm{N}$ and $\mathrm{O})$ of high-melting temperature metals. ${ }^{18)}$ The degassing of hightemperature melting point metals can be explained by the facile vaporization of suboxide during melting at high temperatures and under high vacuum. In this study, the removal mechanism of oxygen from $\mathrm{Ru}$ by the vaporization of suboxide can be represented as $x \mathrm{O}$ (in $\mathrm{Ru})+\mathrm{Ru} \rightarrow \mathrm{RuO}_{x}$ (g). In addition, carbon and nitrogen concentrations in the final $\mathrm{Ru}$ ingot were reduced from those in the powder, from 82 to 7 mass ppm (for C) and from 340 to 14 mass ppm (for $\mathrm{N}$ ). The removal mechanism of carbon from $\mathrm{Ru}$ by decarburization can be represented as $\mathrm{C}$ (in $\mathrm{Ru}$ ) $+\mathrm{O}$ (in $\mathrm{Ru}) \rightarrow \mathrm{CO}(\mathrm{g})$, while the nitrogen concentration in $\mathrm{Ru}$ can be predicted from the vaporization $[\mathrm{N}$ (in $\mathrm{Ru})+\mathrm{N}$ (in $\mathrm{Ru}) \rightarrow \mathrm{N}_{2}$ ] that is caused by the high EB thermal source at high vacuum. ${ }^{19)}$ The gas impurities in the $\mathrm{Ru}$, such as $\mathrm{C}, \mathrm{N}$ and $\mathrm{O}$, were significantly reduced by EB melting to a level below 35 mass ppm from the Ru powder's initial level of around 2,550 mass ppm. Furthermore, $\mathrm{Cl}$ was almost completely removed from the Ru powder (initial level of around 32 mass ppm to below 1 mass ppm) by EB melting. The experimental results show that multiple EB melting provides a sample of 99.9995 mass\% purity by the evaporation of gaseous and metallic impurities.

Figure 6 shows the average grain sizes of the $\mathrm{Ru}$ button ingots prepared by EB melting as a function of melting time. These specimens were polished and sputtered for several hours to obtain the grain feature after the GDMS analyses due to a difficulty of etching technology. The craters (diameter $12 \mathrm{~mm}$ ) on the $\mathrm{Ru}$ ingots were created by glow discharge. The total amount of metallic impurities in the $\mathrm{Ru}$ button ingots after purification changed to 127, 11, 7.6 and 5.3 mass ppm, respectively ((a) to (d) in Fig. 6) from the initial level of 380 mass ppm. The measured average grain sizes of the Ru button ingots as a function of melting time were $1.16,2.24,2.43$ and $2.46 \mathrm{~mm}$ for the premelted sample and the samples melted for 2, 4 and 6 min respectively. When the $\mathrm{Ru}$ button ingot was melted for $2 \mathrm{~min}$, the average grain size increased considerably, to approximately 2 times that of the premelted $\mathrm{Ru}$ button ingot. The average grain size then slightly increased as the melting time was increased further. Generally, the grain size of metals strongly depends upon the other elements involved, such as the alloying elements or impurities. ${ }^{20)}$ An impurity has a large impact on grain growth, especially for high-purity metals. It is known that the amount of impurities in a pure metal leads to smaller grain size due to the impurities on the boundary restricting the grain growth. ${ }^{21)}$ Several researchers reported on the relationship between impurities and the grain size of pure metals. ${ }^{22,23)}$ For instance, Bermingham et al. ${ }^{24)}$ reported that when the $\mathrm{Si}$ concentration in a pure $\mathrm{Ti}$ ingot was increased from 500 to 9,000 mass ppm, the grain size decreased by about $61 \%$. In this study, we also found that the removal of impurities in the $\mathrm{Ru}$ metals by EB melting resulted in an increase in the grain size. This is because there was an enhancement in grain growth from the reduced amount of impurities available to inhibit growth.

\section{Conclusions}

EB melting for $\mathrm{Ru}$ was investigated and the purity of $\mathrm{Ru}$ ingots refined by EB melting was evaluated using GDMS. High-purity ( $5 \mathrm{~N}$ grade) $\mathrm{Ru}$ was achieved after only 6 min of EB melting. The purities achieved after EB melting for 2 and 4 min were 99.9988 and 99.9992 mass\%, respectively. The gaseous impurities in the Ru metals, such as $\mathrm{C}, \mathrm{N}$ and $\mathrm{O}$, were significantly reduced by multiple EB melting from the initial level of around 2,500 mass ppm in the $\mathrm{Ru}$ powder to a level below 35 mass ppm after 6 min of melting. The differences in $R D$ values for each impurity can be explained by the difference in vapor pressure for each element. Furthermore, it was found that the removal of impurities in the $\mathrm{Ru}$ metals by EB melting resulted in an increase in the grain size, since there followed an enhancement in grain growth from the reduced concentration of impurities present. Therefore, it is considered that the high-purity ( $5 \mathrm{~N}$ grade) $\mathrm{Ru}$ ingot obtained by EB melting can be used as a raw material for a sputtering target.

\section{Acknowledgement}

This work was supported by a grant from the fundamental R\&D program for Core Technology of Materials funded by the Ministry of Knowledge Economy, Republic Korea.

\section{REFERENCES}

1) S. Prasad, R. M. Naik and A. Srivastava: Spectrochim. Acta A 70 (2008) 958-965.

2) L. B. Hunt and F. M. Lever: Plat. Met. Rev. 13 (1969) 126-138.

3) C. R. K. Rao and D. C. Trivedi: Coord. Chem. Rev. 249 (2005) 613631.

4) J. P. Greene: Nucl. Instrum. Methods Phys. Res. A 480 (2002) 119123. 
5) K. Samares: Physics and technology of high-k gate dielectrics 5 , Ausgabe 4, The Electrochemical Society, USA (2007).

6) B. K. Lee, J. M. Oh, G. S. Choi, K. I. Rhee, S. W. Lee, S. B. Kim and J. W. Lim: Mater. Trans. 53 (2012) 425-427.

7) D. Elanski, K. Mimura, T. Ito and M. Isshiki: Mater. Lett. 30 (1997) $1-5$.

8) G. S. Choi, J. W. Lim, N. R. Munirathnam and I. H. Kim: Met. Mater. Int. 15 (2009) 385-390.

9) J. W. Lim, G. S. Choi, K. Mimura and M. Isshiki: Met. Mater. Int. 14 (2008) 539-543.

10) K. Vutova, V. Vassileva, E. Koleva, E. Georgieva, G. Mladenov, D Mollov and M. Kardjiev: J. Mater. Process. Technol. 210 (2010) 10891094.

11) J. T. Schriempf: J. Less-Common Met. 9 (1965) 35-39.

12) J. S. Becker and H. J. Dietze: Spectrochim. Acta B 53 (1998) 14751506.

13) G. S. Choi, J. W. Lim, N. R. Munirathnam, I. H. Kim and J. S. Kim J. Alloy. Compd. 469 (2009) 298-303.

14) S. Yuichiro and S. Tsuneo: United States Patent 6,036,741 (2001).
15) H. Gang and U. Tomonori: Hitachi Metals Technical Report 20 (2004) $57-62$.

16) V. Vassileva, G. Mladenov, K. Vutova, T. Nikolov and E. Georgieva: Vacuum 77 (2005) 429-436.

17) J. Otubo, O. D. Rigo, C. Moura Neto and P. R. Mei: Mater. Sci. Eng. A 438-440 (2006) 679-682.

18) Y. Waseda and M. Isshiki: Purification Process and Characterization of Ultra High Purity Metals, (Springer, 2001) pp. 126-137.

19) H. S. Hong and K. S. Lee: J. Alloy. Compd. 360 (2003) 198-204.

20) S. Choudhury and R. Jayaganthan: Mater. Chem. Phys. 109 (2008) 325-333.

21) D. A. Porter and K. E. Easterling: Phase Transformation in Metal and Alloys, (Chapman \& Hall, London, 1992).

22) V. Yamakov, D. Moldovan, K. Rastogi and D. Wolf: Acta Mater. 54 (2006) 4053-4061.

23) D. Horton, C. B. Thomson and V. Randle: Mater. Sci. Eng. A 203 (1995) 408-414.

24) M. J. Bermingham, S. D. McDonald, M. S. Dargusch and D. H. St. John: Scr. Mater. 58 (2008) 1050-1053. 